[0212-7199 (2003) 20: 12; pp 621-623] ANALES DE MEDICINA INTERNA Copyright (C) 2003 ARAN EDICIONES, S.L.

AN MED INTERNA (Madrid) Vol. 20, N. ${ }^{\circ} 12$, pp. 621-623, 2003

\title{
Invaginación intestinal del adulto secundaria a tumores yeyunales con diferenciación neural del sistema autónomo (GAN)
}

\author{
J. A. FRAGUELA MARIÑA, F. ARES FARPÓN, C. Ma FERNÁNDEZ BLANCO, D. \\ ROSALES JUEGA, S. LÓPEZ GARCÍA, C. GÓMEZ FREIJOSO
}

Servicio de Cirugía General "A”. Complejo Hospitalario Juan Canalejo. A Coruña

\begin{abstract}
INTESTINAL INVAGINATION IN ADULT PATIENTS DUE TO JEJUNAL TUMORS WITH NEURAL DIFERENTATION OF AUTONOME $\operatorname{SYSTEM}(G A N)$
\end{abstract}

\section{RESUMEN}

Presentamos dos casos clínicos de invaginación intestinal secundaria a tumores GAN yeyunales que debutan con un episodio de obstrucción intestinal que requirió intervención quirúrgica. Se analizan los métodos diagnósticos, el diagnóstico diferencial y la actitud terapéutica.

PALABRAS CLAVE: Invaginación. Intestino delgado. Tumores del estroma gastrointestinal (GIST). ABSTRACT
We report two clinical cases of intestinal invagination due to jejunal
GAN tumors that were operated on because of an intestinal obstruction.
Diagnostic methods, diferencial diagnosis and therapeutic approach were analized.

KEY WORDS: Invagination. Small bowel. Gastrointestinal stromal tumors (GIST).

Fraguela Mariña JA, Ares Farpón F, Fernández Blanco CM, Rosales Juega D, López García S, Gómez Freijoso C. Invaginación intestinal del adulto secundaria a tumores yeyunales con diferenciación neural del sistema autónomo (GAN). An Med Interna (Madrid) 2003; 20 : 621-623.

\section{INTRODUCCIÓN}

El intestino delgado (ID) representa el $75 \%$ de la longitud total del tracto gastrointestinal y el $90 \%$ de su superficie mucosa. A pesar de ello las neoplasias de esta localización son raras, estimándose su incidencia entre el 1 y $6 \%$ del total de neoplasias gastrointestinales. La invaginación intestinal en adultos es infrecuente, representando el 5\% de todas las causas de obstrucción, decubriéndose un tumor en la cabeza de la misma en la mayoría de los casos (1). El diagnóstico se establece mediante ecografía, TC y tránsito baritado, aunque con frecuencia la filiación definitiva es intraoperatoria tras una laparotomía urgente por obstrucción, hemorragia o perforación.

El tratamiento suele ser quirúrgico con resección del asa afectada, debido generalmente a la imposibilidad de reducción de la intususpección y a la presencia de una tumoración como origen de la misma. Los tumores del estroma gastrointestinal (GIST) con diferenciación neural (GAN) son poco comunes en yeyuno, y su manifestación clínica como invaginación intestinal es excepcional.

\section{CASOS APORTADOS}

Caso 1: Mujer de 25 años con antecedentes de anemia ferropénica diagnosticada hace 3 años que se normalizó tras suplemento oral de hierro y a tratamiento actual con anovulatorios orales y Fluoxetina. Acudió a Urgencias por presentar dolor epigástrico continuo de comienzo brusco acompañado de náuseas y mareo. Hábito intestinal normal. Refiere episodios similares de menor intensidad que relaciona con la ingesta y que ceden con el ayuno. No astenia, anorexia ni adelgazamiento. A la exploración está afebril, TA 80/40, palidez cutáneo-mucosa y el abdomen es blando, depresible, sin defensa ni signos de irritación peritoneal, aunque es doloroso a la palpación en epigastrio con peristaltismo discretamente aumentado. En la analítica destaca un $\mathrm{Ht}^{\circ}$ de $24 \%$ con una $\mathrm{Hb}$ de $7,3 \mathrm{~g} / \mathrm{dl}$ siendo el resto normal. La radiografía de abdomen se informa como íleo reflejo. El TC abdominal pone de manifiesto la presencia de una masa en relación con mesenterio o asa de intestino delgado engrosados, sospechosos de sangrado activo. Se realiza arteriografía que refleja una zona hipervascularizada en epigastrio-hipocondrio izquierdo compatible con tumoración yeyunal, sin signos de sangrado activo (Fig. 1). Se decide intervención quirúrgica y tras la inducción anestésica se palpa una masa abdominal localizada en mesogastrio lisa y móvil. Se realiza una laparotomía supraumbilical, apreciandose intususpección de

Trabajo aceptado: 4 de mayo de 2003

Correspondencia: José Antonio Fraguela Mariña. C/ Gral. Sanjurjo, 48. P-3.4ºD. 15006 A Coruña. e-mail: JAFM@analejo.org. 


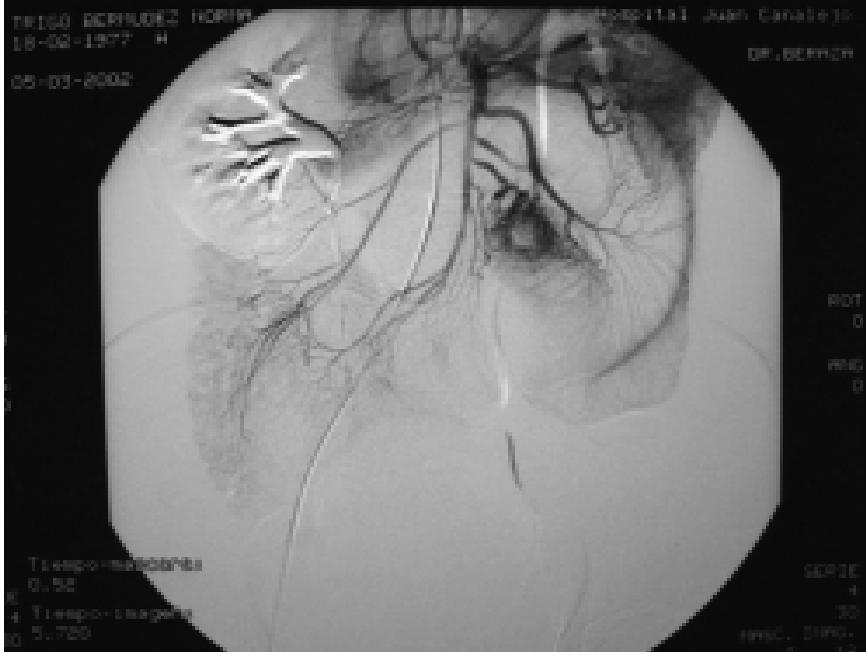

Fig. 1. Arteriografía que muestra una zona de hipervascularización en epigastrio sugestiva de tumoración yeyunal.

un asa yeyunal que es imposible de reducir, por lo que se procede a resección segmentaria de $30 \mathrm{~cm}$ de yeyuno conteniendo una tumoración de 4 x 4 x 2,5 cm que se informó como tumor del estroma gastrointestinal con diferenciación neural del sistema autonómico (GAN). El postoperatorio cursó sin complicaciones, siendo dada de alta en buena situación clínica.

Caso 2: Paciente de 19 años, sin antecedentes de interés que acude a urgencias por presentar un cuadro diarreico con 4-5 deposiciones/dia sin sangre, moco ni pus acompañado de dolor abdominal difuso de tipo cólico de una semana de evolución. En las últimas 48 horas el dolor se ha incrementado y se acompaña de vómitos. Refiere así mismo, astenia, anorexia y adelgazamiento en los últimos 3 meses. A la exploración se aprecia un paciente afectado por el dolor, con palidez de piel y mucosas y $\mathrm{T}^{\mathrm{a}} 37,2^{\circ} \mathrm{C}$. El abdomen es blando y depresible sin defensa ni signos de irritación peritonal. No se palpan masas ni megalias. Existe dolor difuso a la palpación y el peristaltismo está conservado. A la palpación se evidencia un nódulo preesternal subcutáneo. En la analítica destaca un $\mathrm{Ht}^{\circ}$ de $24,9 \%$ y una $\mathrm{Hb}$ de $7,9 \mathrm{~g} / \mathrm{dl}, 21090$ leucocitos, 505.000 plaquetas un TP de $16 \mathrm{seg}$ un TTPA de 26 seg y un TT de 16 seg. La radiografía de tórax muestra dos nódulos pulmonares derechos sugestivos de metástasis (Fig. 2). La radiografía de abdomen es compatible con obstrucción de intestino delgado. En la ecografía abdominal destaca una imagen "en diana" en la región periumbilical compatible con invaginación de intestino delgado. En el TC toraco-abdominal se aprecian dos masas pulmonares en LSD de 5,1 y 3,6 cm así como múltiples nódulos diseminados menores de $1 \mathrm{~cm}$. y una masa en mesogastrio compatible con invaginación intestinal. El paciente es intervenido de urgencia constatándose invaginación secundaria a tumoración de yeyuno, múltiples implantes en yeyuno, mesenterio, ángulo de Treitz y fondo de saco de Douglas. Se realiza resección de segmento de yeyuno, siendo el estudio anatomopatológico diagnóstico de tumor maligno de estroma gastrointestinal con diferenciación neural. Se extirpa el tumor preesternal que se informa como metastásico de tumor de estroma gastrointestinal. Postoperatoriamente el enfermo fue sometido a quimioterapia con Ifosfamida, disminuyendo las masas pulmonares y permaneciendo en buena situación clínica un año después de la cirugía.

\section{DISCUSIÓN}

La invaginación intestinal en adultos es una entidad rara, suponiendo el $5 \%$ de todas las causas de obstrucción y generalmente se asocia a la presencia de un tumor que actúa como

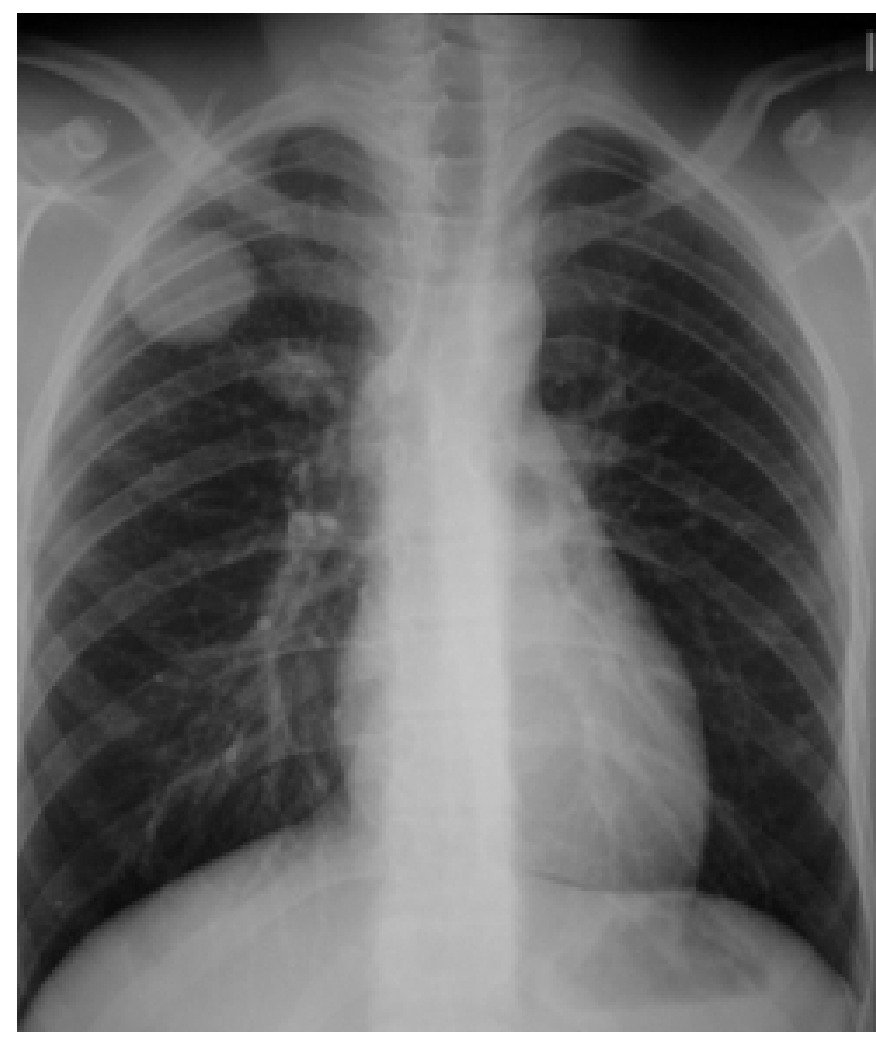

Fig. 2. Nódulos pulmonares metastásicos.

cabeza de la intususpección. Suelen tratarse de tumores benignos en caso de invaginaciones de ID al contrario de las de origen colónico en las que predomina el adenocarcinoma como causa de intususpección (1). Las neoplasias de intestino delgado son lesiones infrecuentes considerándose factores protectores la presencia de contenido líquido y alcalino, el tránsito acelerado, la escasa cantidad de bacterias que lo colonizan, la rápida proliferación de las células mucosas del intestino que inhiben el crecimiento de las células malignas competitivas, la riqueza de tejido linfático con producción de IgA que dificultaría la exposición de la pared intestinal a los agentes carcinógenos como complemento a la base genética probablemente necesaria para el desarrollo de las mismas (2). Se apunta la mayor frecuencia de tumores en los tramos proximales de ID disminuyendo en los más distales conforme aumenta el peristaltismo basal. Así, el $60 \%$ de los tumores benignos del ID se localizan en yeyuno y el $66 \%$ de los malignos en el íleon $(3,4)$. Los dos casos que presentamos son de localización yeyunal. Parece que globalmente existe una ligera mayor preponderancia por el sexo femenino aunque Miles y cols. encontraron, como en nuestros casos, que los tumores malignos son más frecuentes en hombres y los benignos más frecuentes en mujeres (5).Entre los tumores de ID causantes de invaginación, se han descrito lipomas, leiomiomas, leiomiosarcomas, pólipos de Peutz-Jeghers, adenomas, adenocarcinomas y sarcomas. Actualmente los términos leiomioma y leiomiosarcoma tienden a sustituirse gradualmente por un término de mayor extensión como tumores del estroma gastrointestinal (GIST), considerándose los tumores estromales del ID (SIST) una variedad mucho menos común (2). Los GIST se pueden subdividir en cuatro categorías en base a sus caracte- 
rísticas fenotípicas: diferenciación hacia musculatura lisa, con estructura similar a las células neurales del plexo mientérico (GAN), diferenciación mixta e indiferenciados. Se consideran criterios de malignidad el tamaño superior a $5 \mathrm{~cm}$, la necrosis reciente del tumor, hemorragia copiosa independiente del acto quirúrgico, extrema celularidad, marcada atipia y elevada actividad mitótica (2) lo que ha permitido calificar nuestro primer caso como benigno mientras que el segundo representa un estadio tumoral avanzado.

Los síntomas asociados con tumores de ID son: dolor abdominal, hemorragia (que puede ser aguda o crónica) y obstrucción intestinal completa o intermitente $(4,5)$. La invaginación con crisis suboclusivas o diarrea asociada como en nuestros casos es extremadamente excepcional. Habitualmente los tumores malignos son asintomáticos, aunque la presencia de astenia, anorexia y adelgazamiento indican una evolución onerosa de la enfermedad y hasta el $69 \%$ de los pacientes presentan metástasis a distancia en el momento del diagnóstico. Nuestro primer caso referia la presencia de un cuadro de anemia de origen desconocido y crisis suboclusivas que se resolvían con reposo intestinal, mientras que en el segundo permaneció asintomático prácticamente hasta el momento del ingreso hospitalario, salvo la presencia de un síndrome consti-

\section{Bibliografía}

1. Ellis H. Tumors of the small intestine. SeminSurg Oncol 1987; 3: 12-21.

2. Quaglino F, Borello M, et al. Gastrointestinal stromal tumors. Un caso di neoplasia stromale dell'intestino tenue (SIST)dal comportamento biológico incerto. Minerva Chir 2000; 55 (5): 347-51.

3. Del Pino FJ, Benito J, et al. Tumores primarios del intestino delgado. Rev Esp Enferm Ap Digest 1989; 76: 437-442.

4. Desa Laj BridgerJ, Grace PA et al. Primary jejunoileal tumors: A review tucional al historiar detenidamente al paciente. La presencia de una masa a la palpación es un hecho que sólo se apreció en el primer caso una vez relajada la paciente previamente a la laparotomía.

El diagnóstico habitualmente se realiza tras estudio baritado gastrointestinal, ecografía y TC que demuestran la presencia de una tumoración de ID con signos radiológicos de intususpección $(3,4)$. La arteriografía es útil para localizar tumores de origen vascular o sangrado mayor de $0,5-1 \mathrm{ml} / \mathrm{m}$ (4), aunque en nuestro primer caso puso de manifiesto la presencia de una tumoración hipervascularizada dentro de la masa detectada en el TC.

El tratamiento de la intususpección es la resección segmentaria del intestino afecto sobre todo teniendo en cuenta que la cabeza de la invaginación suele ser un tumor cuyo origen es imposible de determinar intraoperatoriamente, aunque tumores obviamente malignos son tratados con amplia resección intestinal que incluya el mesenterio adyacente con los ganglios regionales (4) seguida de quimioterapia como tratamiento neoadyuvante según las características del tumor, aunque las esperanzas están puestas en nuevas terapias del tipo Imatinib con resultados prometedores en los primeros casos analizados (6). of 45 cases. World J Surg 1991; 15 (1): 81-87.

5. Álvarez A, Ciriza C, García J, et al. Invaginación ileal dependiente de leiomioma como causa de obstrucción intestinal intermitente. An Med Interna (Madrid) 1995; 12: 505-507.

6. Guetz des G, Mestier Ph. En fin un traitment efficace dans les sarcomes digestifs indiferencies (tumeurs stromales). J Chir 2002; 139 (5): 268273. 